\title{
A review of 111 anaesthetic patients undergoing cytoreductive surgery and hyperthermic intraperitoneal chemotherapy
}

Sze Ying $\underline{\text { Thong }}{ }^{1}$, mBBs, MMed, Claramae Shulyn $\underline{\text { Chia }}^{2}$, MBBS, MRCS, Oriana $\underline{N g}^{1}$, MBBS, MMed, Grace ${\underline{T a n^{2}}}^{2}$, MBBS, MRCS, Ee Teng $\underline{O n g}^{1}$, MBBS, MMed, Khee Chee $\underline{S o O}^{2}$, MBBS, FRACS, Melissa $\underline{T e O}^{2}$, MBBS, MMed

\begin{abstract}
INTRODUCTION Cytoreductive surgery (CRS) along with hyperthermic intraperitoneal chemotherapy (HIPEC) is the treatment of choice for selected patients with peritoneal carcinomatosis, a previously lethal condition with dismal survival rates.

METHODS We reviewed CRS and HIPEC procedures performed at our centre from January 1997 to December 2012 , focusing on perioperative events and anaesthetic implications.

RESULTS In total, 111 patients underwent 113 procedures. Mean age of the patients was 51.7 (range 14-74) years and $84.1 \%$ were women. Mean duration of surgery was 9 hours 10 minutes \pm 2 hours 56 minutes. Most tumours were ovarian or colorectal in origin, and the mean peritoneal cancer index $(\mathrm{PCl})$ score was $14.3 \pm 8.9$. Mean estimated blood loss was $1,481 \pm 1,064 \mathrm{~mL}$. Mean total intravenous fluids and blood products administered was 8,498 $\pm 3,941 \mathrm{~mL}$. Postoperatively, $79.5 \%$ of the patients needed intensive care, as $75.2 \%$ of the 113 procedures required interval extubation. Patients with lower PCl scores were more likely to be extubated immediately after surgery $(p<0.05) .80 .0 \%$ of patients had coagulopathy postoperatively, and this was associated with longer HIPEC duration $(p<0.05)$. Median lengths of intensive care unit and hospital stays were two days and 14 days, respectively. Longer duration of surgery significantly correlated with longer hospitalisation. Prolonged hospitalisation was due to nosocomial pneumonia, pleural effusions, respiratory failure, sepsis, surgical complications (such as anastomotic or wound dehiscence), and intra-abdominal infections.

CONCLUSION The CRS and HIPEC technique is a major surgery with significant morbidity, as highlighted by the perioperative concerns observed in our study.
\end{abstract}

Keywords: anaesthesia, cytoreductive surgery, intraperitoneal chemotherapy

\section{INTRODUCTION}

Peritoneal carcinomatosis (PC) was previously a lethal condition with dismal survival rates. Cytoreductive surgery (CRS) and hyperthermic intraperitoneal chemotherapy (HIPEC) have been described as the treatment of choice for selected patients with evidence of PC from the gastrointestinal tract, peritoneum, ovaries and the disease of pseudomyxoma peritonei. ${ }^{(1-3)}$ CRS aims to remove macroscopic disease, while HIPEC works synergistically by removing microscopic tumour load at $42^{\circ} \mathrm{C}-43^{\circ} \mathrm{C}$. HIPEC achieves high peritoneal concentrations of chemotherapy but limited systemic absorption. ${ }^{(4)}$

The combination of CRS and HIPEC is a complex procedure with many anaesthetic considerations. There is scant evidence in the literature regarding the anaesthetic management of patients undergoing CRS and HIPEC. In this article, we give a brief overview of CRS and HIPEC, and share the anaesthetic outcomes of patients who underwent the two procedures at our centre. Due to the general paucity of evidence, unless otherwise referenced, recommendations in this article are based on the authors' experience.

The National Cancer Centre Singapore is a tertiary cancer centre with the largest published experience in CRS and HIPEC for colorectal, ovarian, appendiceal and primary peritoneal cancers in Asia. This paper aimed to review all CRS and HIPEC procedures performed at our centre between January 1997 and December 2012, with a focus on perioperative events and anaesthetic implications.

\section{METHODS}

After receiving approval from the Centralised Institutional Review Board of Singapore Health Services, all patients who had undergone CRS and HIPEC at the National Cancer Centre Singapore were included in this study. A total of 111 consecutive patients who had undergone 113 CRS and HIPEC procedures until December 2012 were analysed. Anaesthetic and perioperative data was collected from patients' medical records and the National Cancer Center prospective database. The medical records of patients with complications were reviewed in greater detail.

Patients with PC were considered for CRS and HIPEC if they had appropriate primary tumour histology, were medically fit with an Eastern Cooperative Oncology Group performance status of 0 or 1 , and had no distant metastases. The extent of disease and feasibility of adequate cytoreduction and tumour clearance were examined on computed tomography (CT) or positron emission tomography-CT and discussed at the multidisciplinary tumour board meetings to determine patients' suitability. 
All patients were admitted the day before surgery and reviewed. Baseline full blood count, renal panel, coagulation profile, blood-group crossmatch, electrocardiography and chest radiography were performed. Patients were given $2 \mathrm{~L}$ of polyethylene glycol for bowel preparation and subcutaneous enoxaparin for deep vein thrombosis prophylaxis.

Anaesthetic management was selected by the anaesthetist in charge. All patients were managed according to the standard monitoring of care, which involved continuous monitoring of electrocardiogram, invasive blood pressure, central venous pressure, pulse oximetry, body temperature and hourly urine output. The bispectral index monitor or noninvasive cardiac output monitoring, FloTrac Sensor (EV1000; Edwards Lifesciences Corp, Irvine, CA, USA), was sometimes used. Typically, intravenous induction with propofol and muscle relaxant was performed to facilitate tracheal intubation, and a volatile opioidbased technique was used to maintain the anaesthesia. Arterial samples were drawn at regular intervals for the measurement of electrolytes, acid-base status and haematocrit.

All surgeries were performed with the patient in the LloydDavies position, as this position allowed easy access to all regions of the abdomen. Intermittent pneumatic calf compressors were used in all patients.

Laparotomy was performed with an extended midline incision. The first phase of the surgery involved dissection, adhesiolysis and determination of the extent of peritoneal involvement by the tumour cells. Peritoneal disease burden was assessed using the peritoneal cancer index $(\mathrm{PCl})$, which scores 13 intra-abdominal sites on a scale of 0 (no disease) to 3 (lesion size $>5 \mathrm{~cm}$ ), thus giving a range of possible scores from 0 to $39{ }^{(5)}$ Involved viscera, which might include the gallbladder, spleen, uterus and ovaries in women, and small and/or large bowels, were then resected to remove all macroscopic peritoneal disease, as described by Sugarbaker in 1995. ${ }^{(6)}$

The affected sections of the peritoneum were then stripped. If diaphragmatic stripping was performed, chest drains were inserted before HIPEC to prevent leakage of the chemotherapy drug across the stripped or repaired diaphragm, as the leakage might otherwise exacerbate pleural effusion intraoperatively or in the first few postoperative days. HIPEC was performed after temporary closure of the abdomen. Depending on the tumour origin, heated chemotherapy drug (mitomycin 10-12.5 mg/m² in 1,000 mL of normal saline or cisplatin $50 \mathrm{mg} / \mathrm{m}^{2}$ in $1,000 \mathrm{~mL}$ of normal saline) was infused into the peritoneal cavity for 60-90 minutes. HIPEC works on microscopic disease, targeting lesions $<3 \mathrm{~mm} .{ }^{(7)}$ After HIPEC, bowel anastomosis or stoma creation was performed before final abdominal closure.

Normovolaemia was maintained by ensuring appropriate intravenous fluid and blood replacement for insensible fluid and blood losses that may be gradual and may accumulate over the long duration of surgery. In some instances such as extensive adhesiolysis, blood loss could be extensive. If this occurs in the context of uncorrected hypovolaemia, the patient would develop hypovolaemic shock.

Fluid resuscitation employs the use of crystalloids and colloids, including albumin. In our opinion, the main advantage of colloid over crystalloid is that the former produces less interstitial oedema. End points such as the maintenance of blood pressure within $20 \%$ of the patient's baseline and urine output $>0.5 \mathrm{~mL} / \mathrm{kg} /$ hour were targeted. The maintenance of adequate urine output as a gauge of normovolaemia is particularly critical perioperatively and during HIPEC to minimise the risk of acute renal injury, especially with nephrotoxic drugs such as intraperitoneal cisplatin. If intraperitoneal cisplatin was used, additional fluid (typically, rapid infusion of $500 \mathrm{~mL}$ of crystalloid immediately before and after the instillation of the chemotherapeutic drug) was administered. In such a scenario, the urine output was targeted at $>1 \mathrm{~mL} / \mathrm{kg} /$ hour.

Blood product replacement was guided by clinical estimation of blood loss and targeted haemoglobin levels of 8-10 mg/dL. Base excess and $\mathrm{pH}$ measured intraoperatively also gave indications of the adequacy of tissue perfusion. These blood parameters were measured using an i-STAT portable clinical analyser (Abbott Point of Care Inc, Princeton, NJ, USA) every 2-4 hours. Normothermia was sustained by forced air warming or underbody thermal blanket, bearing in mind that subsequent HIPEC tended to increase the patient's body temperature.

Depending on the patient's premorbid status and intraoperative progress, either the anaesthetic was reversed or the patient was kept intubated and admitted directly to the surgical intensive care unit (SICU) for interval extubation. Generally, patients were kept ventilated and admitted to the SICU due to a combination of the following reasons: massive blood loss and transfusion; metabolic acidosis with base excess $<-8 \mathrm{mEq} / \mathrm{L}$; extended duration of surgery $>10$ hours; severe hypothermia $<35^{\circ} \mathrm{C}$; or unstable haemodynamic status. Otherwise, extubated patients were admitted to the post-anaesthetic care unit before they were managed by step-down care in the high-dependency area or intermediate care unit. Patient-controlled intravenous morphine analgesia was used for the management of pain postoperatively.

Data was analysed using PASW Statistics version 18.0 (SPSS Inc, Chicago, IL, USA). Categorical data was presented as numbers and percentages. Continuous variables were presented as mean \pm standard deviation if they were normally distributed, and as median (range) otherwise. General linear model was used for multivariate analyses of significant factors that affect postoperative complications, extubation, coagulopathy and hospitalisation. A p-value $<0.05$ was considered statistically significant.

\section{RESULTS}

In total, 111 patients underwent 113 procedures. The mean age of the patients was $51.7 \pm 11.6$ (range 14-74) years. The mean height, weight and body mass index were $1.6 \pm 0.1 \mathrm{~m}, 57.0 \pm$ $12.7 \mathrm{~kg}$ and $22.2 \pm 4.4 \mathrm{~kg} / \mathrm{m}^{2}$, respectively. Patient demographics, intraoperative variables and perioperative events are presented in Tables I, II and III, respectively. None of our patients developed immediate postoperative kidney injury, based on the RIFLE criteria. ${ }^{(8)}$

As many as 28 (24.8\%) patients were extubated immediately after surgery, while the remaining $85(75.2 \%)$ patients were admitted to the SICU for ventilatory support. The majority of patients who 
Table I. Medical and surgical histories of patients undergoing cytoreductive surgery and hyperthermic intraperitoneal chemotherapy ( $\mathrm{n}=113$ ).

\begin{tabular}{lc}
\hline Variable & No. (\%) \\
\hline ASA physical status & \\
I & $62(54.9)$ \\
II & $45(39.8)$ \\
III & $6(5.3)$ \\
Gender & \\
Male & $18(15.9)$ \\
Female & $95(84.1)$ \\
Ascites & \\
Yes & $21(18.6)$ \\
No & $92(81.4)$ \\
Ischaemic heart disease & \\
Yes & $3(2.7)$ \\
No & $110(97.3)$ \\
Diabetes mellitus & \\
Yes & $14(12.4)$ \\
No & $99(87.6)$ \\
Hyperparathyroidism & \\
Yes & $22(19.5)$ \\
No & $91(80.5)$ \\
Primary tumour & $109(96.5)$ \\
Ovarian & $4(3.5)$ \\
Colorectal & \\
Appendix mucinous adenocarcinoma & \\
Pseudomyxoma peritonei & $11(9.7)$ \\
Mesothelioma & $3(7.1)$ \\
Primary peritoneal carcinoma & \\
Gastric carcinoma & $35(2.7)$ \\
Yesios & \\
No & \\
\hline
\end{tabular}

ASA: American Society of Anesthesiologists

were admitted to the SICU were extubated on the first ( $\mathrm{n}=59$, $69.4 \%$ ) and second ( $\mathrm{n}=11,12.9 \%$ ) postoperative days. Using multivariate analysis, a higher $\mathrm{PCl}$ score (17 vs. 7) was the only statistically significant factor for patients who were not extubated immediately after surgery $(p<0.05)$. There was a trend toward longer operative time, higher blood loss, and greater blood and fluid replacements in patients who were not extubated immediately after surgery.

In the immediate postoperative period, among the 100 patients with available data, $80(80.0 \%)$ patients had elevated prothrombin time (PT) or/and activated partial prothromboplastin time (aPTT). Patients with postoperative coagulopathy had longer operative times, higher $\mathrm{PCl}$ scores, greater blood loss and larger amounts of blood, frozen plasma, colloid or total fluids administered. However, none of these factors were statistically significant, except for HIPEC duration (63 minutes vs. 58 minutes; $\mathrm{p}<0.05$ ).
For patients who were admitted to the SICU, the median duration before discharge to the intermediate care unit or highdependency area was 2 (range 1-28) days. Eight patients required SICU care for more than a week. Patients who stayed longer in the SICU had longer operative times, higher PCI scores, greater blood loss, larger amounts of total fluids administered and lower intraoperative base excess, although none of these factors were statistically significant.

The median duration to discharge from hospital was 14 (range 7-188) days. There were 19 patients who required hospitalisation of more than 30 days. Patients who required longer hospitalisation (i.e. $>14$ days), as compared to those who had shorter hospitalisation, had higher $\mathrm{PCl}$ scores and longer durations of surgery (10 hours 3 minutes vs. 8 hours 18 minutes), with the latter difference being statistically significant $(p<0.05)$. The reasons for prolonged ICU stay or hospitalisation are summarised in Table IV.

\section{DISCUSSION}

We presented a series of 111 patients for whom 113 CRS and HIPEC procedures were performed at our centre. Although CRS and HIPEC were described by Sugarbaker in 2006, the perioperative outcomes of the procedures have not been robustly reported in the literature. (1) To our knowledge, the present study is the largest series that specifically looked at this combined procedure in terms of its anaesthetic management. Several specific perioperative anaesthetic concerns for peritonectomy were highlighted in our study. These were related to: (a) blood loss and fluid management; (b) analgesia; (c) temperature, airway pressure and acid-base changes; (c) antibiotics; (d) criteria for extubation; and (e) recovery.

In our patient group, the range of blood loss was wide and corresponded with the extent of surgery. Good communication with the surgical team and vigilance in assessing blood loss and fluid status are thus vital. Blood loss can be sudden and torrential, particularly during the cytoreductive phase and stripping of the liver capsule. Drainage of ascites, blood loss and evaporative loss from raw peritoneal surfaces can dramatically deplete intravascular volume. Therefore, appropriate fluid or blood products should be administered in a timely manner, as guided by clinical estimates of blood loss, urine output, haemodynamics, and haemoglobin and acid-base measurements.

The mean volume of fluids and blood products administered to our patients was large, as a permissive fluid regimen was used to replace blood and fluid losses. However, such a regimen predisposes patients to fluid third-spacing and tissue oedema. The main advantage of using colloids, as compared to crystalloids, was less tissue oedema. Options of colloids included hydroxyethyl starch, gelafusine or $5 \%$ albumin, at the discretion of the anaesthetist. A restrictive fluid regimen, on the other hand, may expose patients to haemodynamic instability, tissue hypoperfusion and lactic acidosis, and exacerbate the renal side effects of chemotherapeutic agents.

There is emerging evidence that goal-directed therapy can reduce perioperative mortality and morbidity in patients 
Table II. Intraoperative variables.

\begin{tabular}{|c|c|}
\hline Variable & Mean \pm SD (range) \\
\hline Duration of surgery (hr \& $\mathrm{min})$ & $9 \mathrm{hr} 10 \mathrm{~min} \pm 2 \mathrm{hr} 56 \mathrm{~min}(3 \mathrm{hr} 6 \mathrm{~min}$ to $20 \mathrm{hr} 15 \mathrm{~min})$ \\
\hline Peritoneal cancer index score & $14.3 \pm 8.9(0-39)$ \\
\hline Estimated blood loss (mL) & $1,481 \pm 1,064(200-5,100)$ \\
\hline Hourly urine output (mL/hr) & $93 \pm 57(11-298)$ \\
\hline Crystalloid administered (mL) & $5,852 \pm 2,912(1,000-18,500)$ \\
\hline Intravenous morphine administered (mg) & $21.4 \pm 10.1(5-50)$ \\
\hline \multicolumn{2}{|l|}{ Blood product/colloid administered $(\mathrm{mL})$} \\
\hline Blood $(n=87 ; 77.0 \%)$ & $1,089 \pm 722(250-3,129)$ \\
\hline Fresh frozen plasma $(n=21 ; 18.6 \%)$ & $604 \pm 243(241-1,000)$ \\
\hline Platelet $(n=7 ; 6.2 \%)$ & $476 \pm 279(200-1,000)$ \\
\hline Cryoprecipitate ( $n=1 ; 0.9 \%$ ) & 150 \\
\hline \multicolumn{2}{|l|}{ Temperature $\left({ }^{\circ} \mathrm{C}\right)$} \\
\hline At start & $35.6 \pm 0.6(34.0-37.1)$ \\
\hline Minimum intraoperative temperature & $35.0 \pm 0.7(32.6-37.1)$ \\
\hline Maximum intraoperative temperature & $37.4 \pm 0.8(35.2-39.1)$ \\
\hline At end of surgery & $36.8 \pm 0.9(34.6-39.1)$ \\
\hline Difference (end of surgery to start) & $1.2 \pm 1.0(-1.2$ to 4.0$)$ \\
\hline \multicolumn{2}{|l|}{ Peak airway pressure $\left(\mathrm{cmH}_{2} \mathrm{O}\right)$} \\
\hline Minimum & $17.4 \pm 2.8(12-26)$ \\
\hline Maximum & $25.8 \pm 5.1(17-40)$ \\
\hline Change & $8.4 \pm 4.4(0-20)$ \\
\hline Final pH & $7.33 \pm 0.07(7.00-7.46)$ \\
\hline
\end{tabular}

*Including hydroxyethyl starch, gelafusine and 5\% albumin. SD: standard deviation

Table III. Other perioperative events.

\begin{tabular}{lc}
\hline Variable & No. (\%) \\
\hline Intraoperative urine output $(\mathbf{m L} / \mathbf{k g} / \mathbf{h r})(\mathbf{n}=\mathbf{9 1})$ & $3(3.3)$ \\
$<0.5$ & $88(96.7)$ \\
$>0.5$ & \\
Temperature at end of surgery $\left({ }^{\circ} \mathbf{C}\right)(\mathbf{n}=\mathbf{9 5})$ & $12(12.6)$ \\
$<36.0$ & $62(65.3)$ \\
$36.0-37.4$ & $21(22.1)$ \\
$>37.4$ & $89(79.5)$ \\
Postoperative discharge disposition $\mathbf{( n = 1 1 2 )}$ & $18(16.1)$ \\
Intensive care unit & $5(4.5)$ \\
Intermediate care unit & \\
High-dependency area & $2(1.8)$ \\
Death during same admission $(\mathbf{n}=\mathbf{1 1 3})$ & $60(80.0)$ \\
Yes & $63(5.6)$ \\
No & \\
No. of chest tubes inserted $(\mathbf{n}=\mathbf{1 1 3})$ & $37(32.7)$ \\
0 & $23(20.4)$ \\
Postoperative coagulopathy* $(\mathbf{n}=\mathbf{1 0 0})$ & $53(46.9)$ \\
\hline & \\
\hline
\end{tabular}

Total for some variables does not equate to 113 because of missing data. *Elevated prothrombin time and/or activated partial prothromboplastin time. +Elevated creatinine levels. undergoing high-risk surgeries. ${ }^{(9)}$ Compared to standard fluid therapy, goal-directed therapy using noninvasive cardiac output monitors has been found to result in lower amounts of administered fluid (5.8 L vs. $8.3 \mathrm{~L}$ ) for patients undergoing CRS and HIPEC. ${ }^{(10)}$ As a result, there was an $18 \%$ reduction in risk of abdominal complications, such as infection and anastomotic dehiscence, as well as a ten-day reduction in length of hospitalisation. ${ }^{(10)}$

The pulmonary artery catheter (Swan-Ganz CCOmbo; Edwards Life Sciences, Unterschleissheim, Germany) was not used in our series, as its utility did not justify the potential complications. While pulmonary artery catheters can furnish fascinating physiological data, they have not been shown to alter outcomes. ${ }^{(11)}$ FloTrac Sensor, which was used for recent patients in our series, is a minimally invasive alternative that provides parameters for goal-directed therapy and optimises the haemodynamics in this high-risk surgery.

Coagulopathy, a recognised complication of CRS and HIPEC, is multifactorial, with massive blood transfusion, dilutional coagulopathy, hypothermia, hypocalcaemia, acidosis or HIPEC being known factors. In our study, we have found suggestions that, in longer and more extensive procedures requiring more colloid or blood replacements, the amount of fresh frozen plasma administered to correct PT or aPTT might be insufficient. 
Table IV. Details of patients with prolonged ICU stay ( $>7$ days) or hospitalisation ( $>30$ days).

\begin{tabular}{|c|c|c|c|c|c|c|c|}
\hline \multirow[t]{2}{*}{ Patient no. } & \multirow{2}{*}{$\begin{array}{l}\text { Age }(y r) / g e n d e r / \\
\text { ASA physical } \\
\text { status }\end{array}$} & \multirow{2}{*}{$\begin{array}{l}\text { Duration of } \\
\text { surgery }\end{array}$} & \multirow[t]{2}{*}{ Medical history } & \multirow{2}{*}{$\begin{array}{l}\text { Surgical resections other than } \\
\text { peritonectomy and HIPEC } \\
\text { (PCI score*) }\end{array}$} & \multirow{2}{*}{$\begin{array}{l}\text { Perioperative complications and reasons for } \\
\text { delayed discharge }\end{array}$} & \multicolumn{2}{|c|}{ LOS (day) } \\
\hline & & & & & & ICU & Hospital \\
\hline 14 & 55/F/ASA II & $11 \mathrm{hr} 57 \mathrm{~min}$ & Diabetes mellitus & $\begin{array}{l}\text { Cholecystectomy, splenectomy, } \\
\text { right hemicolectomy with small } \\
\text { bowel resection, low anterior } \\
\text { resection (39) }\end{array}$ & $\begin{array}{l}\text { Developed nosocomial pneumonia, required } \\
\text { prolonged ventilatory support and extubated on } \\
\text { POD } 7\end{array}$ & 9 & 18 \\
\hline 23 & $35 / F / A S A I I I$ & $10 \mathrm{hr} 46 \mathrm{~min}$ & $\begin{array}{l}\text { Acromegaly, pituitary } \\
\text { adenoma status post } \\
\text { radiation therapy and } \\
\text { resection }\end{array}$ & $\begin{array}{l}\text { Omentectomy, right hemicolectomy, } \\
\text { anterior resection, splenectomy, } \\
\text { resection of metastatic nodules, } \\
\text { peritonectomy (25) }\end{array}$ & $\begin{array}{l}\text { Intraoperative blood loss } 2,000 \mathrm{~mL} \text {, postoperative } \\
\text { respiratory depression due to morphine, pulmonary } \\
\text { collapse-consolidation, respiratory insufficiency } \\
\text { due to pain }\end{array}$ & 4 & 31 \\
\hline 110 & 66/F/ASA II & $11 \mathrm{hr} 22 \mathrm{~min}$ & $\begin{array}{l}\text { Hypertension, } \\
\text { thalassaemia minor }\end{array}$ & $\begin{array}{l}\text { Splenectomy, cholecystectomy, right } \\
\text { hemicolectomy, anterior resection, } \\
\text { peritonectomy (12) }\end{array}$ & $\begin{array}{l}\text { Respiratory failure due to bilateral } \\
\text { consolidation, sepsis, fast AF; intra-abdominal } \\
\text { collections requiring percutaneous drainage on } \\
\text { POD 15; recurrent bilateral pulmonary lower lobe } \\
\text { consolidation, effusion and collapse; pre-sacral } \\
\text { collection treated conservatively }\end{array}$ & 10 & 33 \\
\hline 19 & $47 / F / A S A I$ & $9 \mathrm{hr} 15 \mathrm{~min}$ & - & $\begin{array}{l}\text { Total colectomy with ileorectal } \\
\text { anastomosis, small bowel resection } \\
\text { and cholecystectomy (28) }\end{array}$ & $\begin{array}{l}\text { Acute kidney injury, Klebsiella bacteraemia; } \\
\text { Enterococcus and Klebsiella wound infections }\end{array}$ & 5 & 34 \\
\hline 94 & $65 /$ F/ASA I & $10 \mathrm{hr} 00 \mathrm{~min}$ & - & $\begin{array}{l}\text { Cholecystectomy, appendicectomy, } \\
\text { small bowel resection }\end{array}$ & Nosocomial pneumonia and MRSA bacteraemia & 2 & 35 \\
\hline 103 & 55/F/ASA II & $13 \mathrm{hr} 20 \mathrm{~min}$ & Diabetes mellitus & $\begin{array}{l}\text { Cholecystectomy, ultralow anterior } \\
\text { resection (29) }\end{array}$ & $\begin{array}{l}\text { Hypokalaemia, hyponatraemia and } \\
\text { hypomagnesaemia due to high stoma output }\end{array}$ & 3 & 36 \\
\hline 98 & 46/F/ASA I & $12 \mathrm{hr} 00 \mathrm{~min}$ & - & $\begin{array}{l}\text { Adhesiolysis, liver biopsy, } \\
\text { anterior resection, hysterectomy, } \\
\text { bilateral salpingo-oophorectomy, } \\
\text { vaginectomy, resection bladder } \\
\text { cuff, splenectomy, omentectomy, } \\
\text { defunctioning ileostomy }\end{array}$ & $\begin{array}{l}\text { POD } 2 \text { postoperative bleeding requiring } \\
\text { exploratory laparotomy; sepsis and candidaemia; } \\
\text { intra-abdominal collections requiring percutaneous } \\
\text { drainage; persistent fever due to drug and/or } \\
\text { malignant fever }\end{array}$ & 4 & 36 \\
\hline 106 & $38 / F / A S A I$ & $12 \mathrm{hr} 30 \mathrm{~min}$ & - & $\begin{array}{l}\text { Total colectomy, small bowel } \\
\text { resection (13) }\end{array}$ & $\begin{array}{l}\text { Extubated on POD } 1 \text { and discharged from ICU; } \\
\text { POD } 4 \text { readmitted to ICU for pneumonia and } \\
\text { respiratory failure requiring intubation; DIVC; } \\
\text { possible leak of chemotherapy drug into the pleural } \\
\text { space; anastomotic leak; small bowel perforation } \\
\text { requiring defunctioning loop jejunostomy; } \\
\text { percutaneous drainage for intra-abdominal } \\
\text { abscess due to Escherichia coli and Acinetobacter } \\
\text { baumannii; sick euthyroid syndrome }\end{array}$ & 14 & 37 \\
\hline 15 & $58 / F / A S A ~ I$ & $8 \mathrm{hr} 30 \mathrm{~min}$ & - & $\begin{array}{l}\text { Anterior resection, splenectomy and } \\
\text { cholecystectomy with } \\
\text { defunctioning loop ileostomy (19) }\end{array}$ & $\begin{array}{l}\text { POD } 12 \text { bilateral pleural effusion, consolidation } \\
\text { and sepsis secondary to Pseudomonas aeruginosa } \\
\text { (P. aeruginosa); POD } 17 \text { subhepatic collection due } \\
\text { to } P \text {. aeruginosa requiring percutaneous drainage }\end{array}$ & 2 & 41 \\
\hline
\end{tabular}




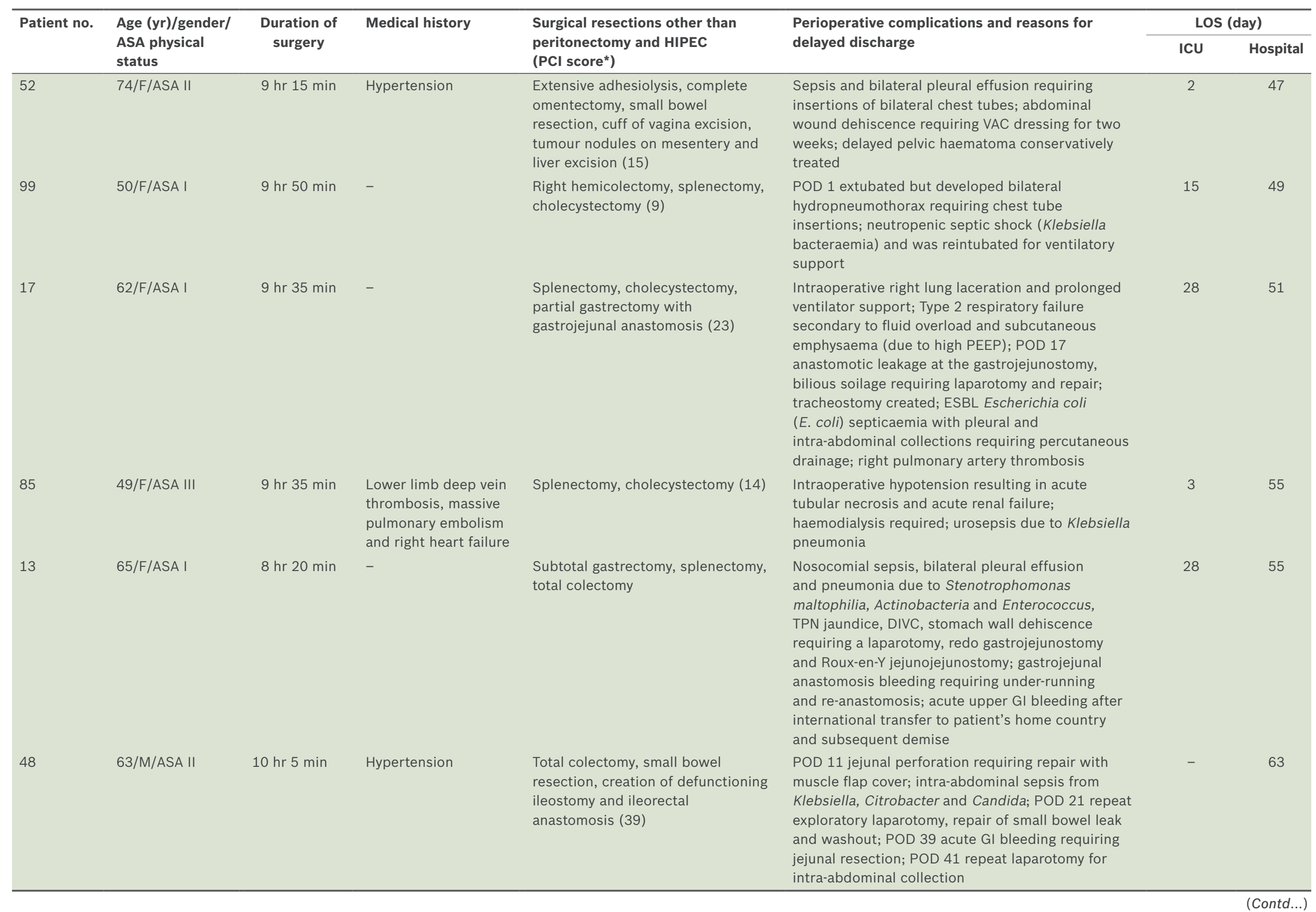




\begin{tabular}{|c|c|c|c|c|c|c|c|}
\hline \multirow[t]{2}{*}{ Patient no. } & \multirow{2}{*}{$\begin{array}{l}\text { Age (yr)/gender/ } \\
\text { ASA physical } \\
\text { status }\end{array}$} & \multirow{2}{*}{$\begin{array}{l}\text { Duration of } \\
\text { surgery }\end{array}$} & \multirow[t]{2}{*}{ Medical history } & \multirow{2}{*}{$\begin{array}{l}\text { Surgical resections other than } \\
\text { peritonectomy and HIPEC } \\
\text { (PCI score*) }\end{array}$} & \multirow{2}{*}{$\begin{array}{l}\text { Perioperative complications and reasons for } \\
\text { delayed discharge }\end{array}$} & \multicolumn{2}{|c|}{ LOS (day) } \\
\hline & & & & & & ICU & Hospital \\
\hline 70 & 37/M/ASA I & $11 \mathrm{hr} 6 \mathrm{~min}$ & - & Splenectomy (27) & $\begin{array}{l}\text { POD } 11 \text { bilateral pleural effusion requiring reinsertion } \\
\text { of chest drains; POD } 18 \text { anastomotic leakage of food } \\
\text { debris from stomach remnant requiring laparotomy, } \\
\text { adhesiolysis and wedge resection of stomach; } \\
\text { developed subsequent intra-abdominal abscess; POD } \\
28 \text { left hypochondrium and abdominal collection } \\
\text { requiring percutaneous drainage; POD } 44 \text { left iliac } \\
\text { fossa collections requiring percutaneous drainage; } \\
\text { POD } 55 \text { new left hypochondrium collection after } \\
\text { previous drain removal, new percutaneous drain } \\
\text { inserted; POD } 51 \text { acute pethidine withdrawal }\end{array}$ & 1 & 63 \\
\hline 56 & 63/F/ASA II & $9 \mathrm{hr} 20 \mathrm{~min}$ & - & Splenectomy, cholecystectomy (22) & $\begin{array}{l}\text { POD } 15 \text { urosepsis from E. coli, Klebsiella and } \\
\text { Candida; POD } 20 \text { left hydropneumothorax requiring } \\
\text { chest drain; intra-abdominal abscess requiring } \\
\text { percutaneous drainage; POD } 40 \text { persistent multiple } \\
\text { intraperitoneal fluid collections }\end{array}$ & - & 76 \\
\hline 10 & 68/F/ASA II & $10 \mathrm{hr} 50 \mathrm{~min}$ & Hypertension & $\begin{array}{l}\text { Right hemicolectomy, low } \\
\text { anterior resection, splenectomy, } \\
\text { omentectomy (24) }\end{array}$ & $\begin{array}{l}4 \mathrm{~L} \text { intraoperative blood loss; POD } 1 \text { bleeding in the } \\
\text { pancreas and diaphragm requiring laparotomy; POD } \\
7 \mathrm{AF} \text { due to sepsis; acute renal failure requiring } \\
\text { SLED; urosepsis, bilateral hydronephrosis needing } \\
\text { PCN; wound infection; multiple interconnecting } \\
\text { fistulae between bladder, rectum and vagina }\end{array}$ & 11 & 77 \\
\hline 100 & 56/F/ASA I & $16 \mathrm{hr} 7 \mathrm{~min}$ & - & $\begin{array}{l}\text { Cystoscopy and bilateral T6 } \\
\text { ureteric stenting, laparotomy, } \\
\text { peritonectomy, anterior resection, } \\
\text { right hemicolectomy, bladder repair, } \\
\text { cholecystectomy, omentectomy }\end{array}$ & $\begin{array}{l}\text { Inadvertent vesicostomy repaired intraoperatively; } \\
\text { POD } 12 \text { burst abdomen requiring laparotomy, } \\
\text { washout and tension suture; POD } 26 \text { massive PR } \\
\text { bleeding and hypotensive shock requiring intubation } \\
\text { and resuscitation; bladder and bowel defects from } \\
\text { primary surgery with feculent content leakage from } \\
\text { abdominal wound requiring drainage and repair; } \\
\text { poor wound healing; pleural effusion, pneumonia, } \\
\text { respiratory failure and septic shock; E. coli and } \\
\text { Enterococcus subphrenic abscess requiring } \\
\text { percutaneous drainage; adrenal insufficiency; } \\
\text { recurrent pneumonia, sepsis, respiratory failure and } \\
\text { repeat intubation and ventilatory support needed; } \\
\text { subsequent intracranial bleeding leading to demise }\end{array}$ & $\begin{array}{l}\text { Multiple } \\
\text { admissions }\end{array}$ & 188 \\
\hline
\end{tabular}

*Some PCI values were not available due to missing data. AF: atrial fibrillation; ASA: American Society of Anesthesiologists; DIVC: disseminated intravascular coagulation; ESBL: extended spectrum beta-lactamases; F: female; Gl: gastrointestinal; HIPEC: hyperthermic intraperitoneal chemotherapy; ICU: intensive care unit; LOS: length of stay; M: male; MRSA: multidrug-resistant Staphylococcus aureus; PCl: peritoneal cancer index; PCN: percutaneous nephrostomy; PEEP: positive end-expiratory pressure; POD: postoperative day; PR: per rectum; SLED: sustained low efficiency dialysis; TPN: total parenteral nutrition; VAC: vacuum-assisted closure 
Large doses of morphine were required for effective analgesia in our patients due to the long duration of surgery, extensive resections and large fluid shifts involved. However, the main disadvantages of opioid-based analgesia are respiratory depression and inadequate analgesia due to its ceiling analgesic effect. This may have accounted for the high rate of postoperative ventilatory support needed in our cohort.

Epidural analgesia is not commonly used for the following reasons: (a) hypotension as a result of thoracic epidural analgesia may confuse the clinical determination of fluid status; (b) coagulopathy may predispose the patient to epidural haematoma; and (c) postoperative infections and sepsis are not uncommon in this group of patients. Therefore, the risk of epidural-related infection is not immaterial. Other analgesic options worth considering are single or continuous paravertebral or subcostal transversus abdominis plane blockade. Paravertebral blocks, which have fewer contraindications than central neuraxial blocks, provide excellent intraoperative anaesthesia and postoperative analgesia. There have not been any reports of systemic toxicity despite the large doses of local anaesthetic required in paravertebral blocks, and the incidence of pneumothorax and hypotension is low. ${ }^{(12)}$

Other consequences of HIPEC include changes in body temperature and airway pressure. After anaesthesia induction, the patient's body temperature is allowed to drift toward the lower limit of normal, as the body temperature will increase by a mean of $1{ }^{\circ} \mathrm{C}-2^{\circ} \mathrm{C}$ while HIPEC is being performed. In some patients who develop hyperthermia, active cooling measures may be necessary during or after HIPEC. Therefore, the challenge is to maintain normothermia during the cytoreductive phase to minimise the ill effects of hypothermia while avoiding hyperthermia during the HIPEC phase.

Due to the volume of intravenous fluid administration, diaphragmatic peritoneal stripping and/or intraperitoneal chemotherapy, pleural effusion (commonly bilateral) is often observed. This and the increase in intra-abdominal pressure during HIPEC explain the mean rise in peak airway pressure in excess of $8 \mathrm{cmH}_{2} \mathrm{O}$. Abdominal filling during HIPEC increases intra-abdominal pressure, which in turn causes cephalad shift of the diaphragm to increase airway pressures and reduce functional residual capacity. These changes, which adversely affect oxygenation and cardiac output, usually do not impact otherwise fit normovolaemic patients clinically. The insertion of chest drains prior to the commencement of HIPEC mitigates the increase in peak airway pressures due to the formation of pleural effusions. Changes in ventilatory parameters to accommodate changes in airway pressures are usually not necessary.

There is also a need to ensure sufficient antibiotic prophylaxis. In our study, prophylactic antibiotics with a broad-spectrum, Gram-negative and anaerobic cover, usually a third-generation cephalosporin (e.g. ceftriaxone and metronidazole), were administered at induction. Redosing of antibiotics at the requisite intervals is important, as the duration of surgery may extend beyond the typical single-dose coverage. Earlier redosing should be considered, especially in the face of rapid blood loss and transfusion. Insufficient antibiotic coverage runs the risk of Gram-negative septicaemia, in view of the extensive bowel resection often required in the background of large, exposed and bleeding surface areas. This can have the disastrous consequence of overwhelming sepsis.

There is no standard criterion for extubation, although duration of surgery, the patient's body temperature, and the amount of blood loss, opioids used and fluids administered are likely to predict the adequacy of unsupported postoperative ventilation. The final acid-base balance and blood indices will also provide an indication. In the present study, none of these factors, except $\mathrm{PCl}$ score, was shown to be statistically significant between patients who were extubated immediately following surgery and those who were not. In our study, $\mathrm{PCl}$ score may be a surrogate for the extent of surgery.

In terms of recovery, although the median number of days to discharge in our study was 14 days, the range (i.e. 7-188 days) was wide. The main reasons that hampered recovery in some patients were repeat procedures or severe postoperative infections. Repeat surgeries were indicated for the treatment of bleeding, anastomosis dehiscence, wound dehiscence and abscess drainage. Interventional radiological procedures were necessary for intraabdominal abscess drainage or chest drain insertions. Severe nosocomial infections affecting the pulmonary, intra-abdominal or urogenital systems were not uncommon. Few patients required temporary haemodialysis for acute kidney injury as a result of these complications. Despite the eventful recovery seen in some of our patients, all except two survived to recovery and discharge.

Kajdi et al analysed 57 CRS and HIPEC procedures performed at their centre over a three-year period. ${ }^{(13)}$ Compared to our cohort, anaesthesia was maintained with propofol and thoracic epidural analgesia in $64.6 \%$ and $78.9 \%$ of their patients, respectively. Despite a lack of standard protocol, their preferred fluid strategy was that of restrictive transfusion management and extensive haemodynamic monitoring, including PiCCO (Pulsion Medical Systems, Munich, Germany) and pulmonary artery catheter. In Kajdi et al's study, the ICU admission rate (93.0\%) and median hospital stay (17; range 9-259 days) were higher than those of our cohort. With limited data on other variables, it is difficult to conclude if a restricted fluid management strategy and/or thoracic epidural analgesia would explain their higher rate of immediate postoperative extubation compared to our cohort $(42.1 \%$ vs. $24.8 \%)$. Data from their study also suggested that the rate of major surgical complications increased significantly with longer operative time and a greater need for blood transfusion. ${ }^{(13)}$ This is not surprising, as both are surrogates for more extensive operations or intraoperative surgical complications.

Schmidt et al described a retrospective case series of 78 patients who had undergone CRS and HIPEC. ${ }^{(14)}$ Unlike Kajdi et al's study ${ }^{(13)}$ and the present study, their median procedure time was shorter at 5 hours 42 minutes and median blood loss was lower at $600 \mathrm{~mL}$, suggesting that less extensive surgeries were performed. There was also a trend toward earlier extubation in patients who received epidural analgesia compared to those who received opioid analgesia. ${ }^{(14)}$ 
The flaws of retrospective studies were inevitable in our study. We were unable to draw a cause-and-effect relationship between the amount of intraoperative fluid strategy and postoperative outcomes. Due to the small number of patients receiving epidural analgesia in our cohort, we were not able to analyse if its use and its opioid-sparing effect facilitated earlier postoperative extubation, although the benefits of epidural analgesia have been shown in other surgeries and the opioid-sparing effects of regional anaesthesia is an outcome of interest. ${ }^{(15)}$ Our experience was drawn over a period of 16 years, during which surgical and anaesthesia techniques have improved. It is thus likely that a patient presenting for CRS and HIPEC today will benefit from our learning curve.

At this juncture, there is insufficient data to conclude the efficacy of specific anaesthetic interventions, such as the use of regional anaesthesia or restrictive fluid management strategy using advanced haemodynamic-monitoring techniques. Until further evidence is available, the use of advanced haemodynamic monitors, such as pulmonary artery catheters or other noninvasive cardiac monitors, will be considered on a caseby-case basis. As the postoperative recovery of these patients may be complicated and eventful, a concerted multidisciplinary effort following a coordinated clinical pathway or protocol may improve outcomes.

In conclusion, as the CRS and HIPEC technique is a major complex surgery with significant morbidity, its perioperative management is a challenge for anaesthetists. Even though many patients who present for this surgery are relatively young and without significant comorbidity, the extensive procedure often results in multisystemic derangements that include the cardiorespiratory system, fluid and acid-base balance as well as body temperature. The present study has highlighted some of the perioperative concerns associated with CRS and HIPEC. We look forward to the development of an optimal anaesthetic technique in conjunction with evidence-based medicine.

\section{ACKNOWLEDGEMENT}

We would like to thank Mr Mrinal Kumar, Division of Surgical Oncology, National Cancer Centre, Singapore, for his help with the statistical analysis.

\section{REFERENCES}

1. Sugarbaker PH. New standard of care for appendiceal epithelial neoplasms and pseudomyxoma peritonei syndrome? Lancet Oncol 2006; 7:69-76.

2. Bryant J, Clegg AJ, Sidhu MK, et al. Systematic review of the Sugarbaker procedure for pseudomyxoma peritonei. Br J Surg 2005; 92:153-8.

3. Teo M. Peritoneal-based malignancies and their treatment. Ann Acad Med Singapore 2010; 39:54-7.

4. Jacquet $\mathrm{P}$, Averbach $\mathrm{A}$, Stephens $\mathrm{AD}$, et al. Heated intraoperative intraperitoneal mitomycin $C$ and early postoperative intraperitoneal 5-fluorouracil: pharmacokinetic studies. Oncology 1998; 55:130-8.

5. Harmon RL, Sugarbaker PH. Prognostic indicators in peritoneal carcinomatosis from gastrointestinal cancer. Int Semin Surg Oncol 2005; 2:3.

6. Sugarbaker PH. Peritonectomy procedures. Ann Surg 1995; 221:29-42.

7. Witkamp AJ, de Bree E, Van Goethem R, Zoetmulder FA. Rationale and techniques of intra-operative hyperthermic intraperitoneal chemotherapy. Cancer Treat Rev 2001; 27:365-74.

8. Bellomo R, Ronco C, Kellum JA, Mehta RL, Palevsky P; Acute Dialysis Quality Initiative workgroup. Acute renal failure-definition, outcome measures, animal models, fluid therapy and information technology needs: the Second International Consensus Conference of the Acute Dialysis Quality Initiative (ADQI) Group. Crit Care 2004; 8:R204-12.

9. Cecconi M, Corredor C, Arulkumaran N, et al. Clinical review: Goal-directed therapy-what is the evidence in surgical patients? The effect on different risk groups. Crit Care 2013; 17:209.

10. Colantonio L, Claroni C, Fabrizi L, et al. A randomized trial of goal directed vs. standard fluid therapy in cytoreductive surgery with hyperthermic intraperitoneal chemotherapy. J Gastrointest Surg 2015; 19:722-9.

11. Richard C, Warszawski J, Anguel N, et al; French Pulmonary Artery Catheter Study Group. Early use of the pulmonary artery catheter and outcomes in patients with shock and acute respiratory distress syndrome: a randomized controlled trial. JAMA 2003; 290:2713-20.

12. Richardson J, Lönnqvist PA, Naja Z. Bilateral thoracic paravertebral block: potential and practice. Br J Anaesth 2011; 106:164-71.

13. Kajdi ME, Beck-Schimmer B, Held U, et al. Anaesthesia in patients undergoing cytoreductive surgery with hyperthermic intraperitoneal chemotherapy: retrospective analysis of a single centre three-year experience. World J Surg Oncol 2014; 12:136

14. Schmidt C, Creutzenberg M, Piso P, Hobbhahn J, Bucher M. Peri-operative anaesthetic management of cytoreductive surgery with hyperthermic intraperitoneal chemotherapy. Anaesthesia 2008; 63:389-95.

15. Manion SC, Brennan TJ. Thoracic epidural analgesia and acute pain management. Anesthesiology 2011; 115:181-8. 